\title{
The Potential for Co-production in Developing Violence against Women Services in Wales
}

\author{
Melanie McCarry*, Cath Larkins**, Vashti Berry***, Lorraine Radford ${ }^{\dagger}$ \\ and Nicky Stanley ${ }^{\dagger \dagger}$
}

*School of Social Work and Social Policy, University of Strathclyde

E-mail: melanie.mccarry@strath.ac.uk

** School of Social Work, Care and Community, University of Central Lancashire

E-mail: CLarkins@uclan.ac.uk

*** University of Exeter Medical School

E-mail:V.Berry@exeter.ac.uk

${ }^{\dagger}$ School of Social Work, Care and Community, University of Central Lancashire

E-mail: Iradford@uclan.ac.uk

${ }^{\dagger}$ School of Social Work, Care and Community, University of Central Lancashire

E-mail: nstanley@uclan.ac.uk

The UK Conservative government has committed to increasing funding for domestic violence and abuse (DVA) services in England but this has not been extended to Wales. Wales has however made clear commitments to developing these services, through the Violence against Women, Domestic Abuse and Sexual Violence (Wales) Act 2015. This article draws on focus groups and interviews with fifty-three service users and thirty-one purposively selected service providers to explore their perspectives on Violence Against Women (VAW) service provision in Wales. There are clear shared priorities and some tensions between service user and provider perspectives on appropriate services. Drawing on the long history of intermediate co-production in VAW services, the article argues that co-production at the strategic level is now needed. This would provide an arena for resolving tensions, setting standards and developing funding criteria to enable coproduced VAW policy and build resistance to funding cuts.

Key words: Violence against women, service users, providers, co-production, services.

\section{Introduction}

In a context of constraints on public spending in the UK, the violence against women (VAW) sector has been disproportionately affected (Women's Aid, 2013). Forced to compete for limited funds, many such organisations are struggling to stay afloat (Towers and Walby, 2012) despite UK government recognition of the expertise of this sector and the cost-effectiveness of its work (Walby, 2004, 2009, 2014; Home Office, 2014a). Home Office acknowledgement that in the UK in 2012-13 an estimated 1.2 million women experienced domestic abuse and over 330,000 experienced sexual assault (Home Office, 2014 b) has led to an additional $£ 42$ million funding from the so-called 'tampon tax' being allocated to domestic violence services in England. However, this funding is not being directed to Wales (Butler, 2015). 
As is the case internationally and in the rest of the UK, VAW, domestic abuse and sexual violence are significant problems in Wales. Estimates indicate that about 11 per cent of women and 5 per cent of men in Wales are affected by domestic abuse each year with young people aged sixteen to twenty-four particularly at risk (Robinson et al., 2012). When lifetime data are included, significantly more women (31 per cent) than men (18 per cent) in England and Wales are victims of domestic abuse (Smith, 2012). Robinson and colleagues (2012) estimate that 3.2 per cent of women and 0.7 per cent of men in Wales are affected by sexual violence (although the authors recognise that the evidence base is far from clear and there are no longitudinal data patterns for Wales). According to Welsh Women's Aid (2016), in 2014/15 there were more than 47,000 incidents of domestic abuse reported to the police in Wales, over 124,000 victims reported a sexual offence and 12,274 adults and 4,346 children were referred to Welsh Women's Aid members for support.

In 2005, the Welsh Government published its first national strategy, Tackling Domestic Abuse, which adopted a rights-based framework guaranteeing the right of every citizen to live a life free from violence and abuse (Welsh Government, 2005). This was followed by the Right to be Safe strategy, a six-year strategy focused on four key areas: prevention and awareness raising, supporting victims, improving the response of criminal justice services, as well as health (and related) services (Welsh Government, 2010). The Welsh Government (2012) white paper set a course for improved education and awareness and more integrated services. In 2013, following a proposal for a new Bill to address genderbased violence, the Welsh government recognised the need to better understand the current service landscape in Wales and to identify effective, evidence-based interventions for funding priorities. The authors were commissioned to undertake an independent review of services. Since publication of the review (Berry et al., 2014), the Welsh Government have passed the Violence against Women, Domestic Abuse and Sexual Violence (Wales) Act 2015 (hereafter called the 2015 Act). This has prevention, protection and support at its core, and 'places duties on the Welsh Ministers, County and County Borough Councils ('Local Authorities') and Local Health Boards to prepare and publish strategies aimed at ending domestic abuse, gender-based violence and sexual violence' (National Assembly for Wales, 2015).

Devolution and divergent policy environments in Wales have had implications for a coordinated response to VAW. The Government of Wales Act 1998 devolved some budgetary powers to the Welsh Assembly, although this devolution was limited to health, education and local government services. Policing and criminal justice continue to be the responsibility of the central UK government. In April 2012, the UK signed the Istanbul Convention and has thus committed itself, in principle, to delivering a comprehensive framework of measures to support victims of male violence and abuse, including specialist services. The Convention also endorses a framework of integrated services, recognising that a multi-agency, multi-partnership approach is the most effective. The UK Government has a strategy on Violence Against Women and Girls (Home Office, 2014a) but has adopted a neutral, non-gendered working definition of domestic violence, whilst the Welsh Government has pursued a strategy that highlighted the gendered nature of violence and abuse, resembling the strategy in Scotland (see McCarry and Lombard, 2016).

Despite the divergence between UK-wide approaches and Welsh policy, UK agendas continue to affect service provision within Wales (see Matczak et al., 2011). In recent years, the Independent Domestic Violence Advisors (IDVAs), the Independent Sexual 
Violence Advisors (ISVAs) and Specialist Assault Referral Centres (SARCs) have been created to provide women with sensitive and specialist support. Specialist Domestic Violence Courts (SDVCs) have also spread across the UK, and the Home Office has signalled its intention to continue support for these. At the local level, there have been inter-agency initiatives, such as the Multi-Agency Risk Assessment Conferences (MARACs) that assess and co-ordinate work on high-risk domestic violence cases. However, regardless of their success in Wales (see Robinson et al., 2012), these are not yet protected in statute. In a context where there is strain between devolved and centralised commissioning arrangements, the tension between national and local partnerships, together with the need to ensure overarching standards of quality while encouraging innovation and fit with local need, present particular challenges for the Welsh Government's strategic funding decisions.

In 2013-14, the Welsh Government provided nearly $£ 4.5$ million funding across Wales to 'support effective services to victims of violence against women, domestic abuse and sexual violence and their families' (Welsh Government, 2014: 9). However, as noted above, Wales has not benefited from the 'tampon tax'. In the current climate of austerity, it is essential that decisions about public spending are based on clear service priorities. However, definitions of 'a good service' are disputed. Randomised control trials are considered the gold standard of evidence for effective services but there are few such robust evaluations of VAW services that can be used to inform service delivery (NICE, 2013; Berry et al., 2014). Understanding of service users' perspectives on good service delivery is also limited, and if services are to be effective in meeting the needs of women and children, their views must be included in service development (Hague and Mullender, 2006).

Alongside evidence-based decision making and effectiveness in policy and service planning, calls for user involvement emerged towards the end of the twentieth century through the growth of service user movements and the development of market-led and personalised approaches (Beresford, 2008). This is part of a much longer history in which the status and practices of citizenship have been contested by feminist theorists and other activists, arguing that the citizenship proposed by liberal democracy fails to recognise class, race, gender and other relatively enduring patterns of disadvantage. Indeed, it has been argued that the multiple discriminations faced by women restrict their ability to enjoy full citizenship, negatively impacting on their enjoyment of citizenship rights and simultaneously negatively affecting civic society due to their restricted, and restrictive, contributions (Hooks, 1982). In exclusionary definitions, decision-making and rights provisions purport to be difference blind, yet citizenship is a practice of identifying the differences that give individuals entitlement to, or exclusion from, multi-layered tiers of government and collectives (Yuval-Davis, 1997).

Most recently, service user involvement is being framed as co-production - a 'slippery' concept with a long history (SCIE, 2015). Co-production can embrace: 'descriptive' responsibilisation, in which service users are expected to self-manage their care and comply with expectations about what they will contribute to their own well-being; 'intermediate' forms of engagement with and consultation by services and policy makers, where views are expressed but decisions about resource allocation are made elsewhere; and, at its most 'transformative', the transfer of resource and decision making from managers to frontline staff and citizens (Needham and Carr, 2009: 6). This transformative form of co-production requires reciprocity and reflexivity 
such that citizens and professionals change their perceptions of themselves and their roles, and develop trust in each other (Durose and Richardson, 2016). Bovaird et al. (2016: 17) argue that collective co-production only occurs when 'both citizens and professionals make a significant contribution', and this underlines the distinction between co-production and self-help or provision of information without opportunities to influence decisions.

The focus on co-production therefore also links to the notion of active citizenship, in which social contributions, for example, to provide unpaid care or manage services, are a key responsibility ascribed to individual citizens (Yuval-Davis, 1997). There is a long history of feminist active citizenship in women's involvement in establishing their own domestic violence/abuse user-led services and co-produced services. Fifteen years ago, Hague and colleagues (2001) noted that the vast majority of refuges in Wales gathered service users' views on services, and some included service users on management committees. Before that, the refuge movement provided social contributions to the care of others in ways that might be described as activist citizenship (Isin, 2009), that is, through political acts or protest that challenged establish notions of social rights and called for recognition of women's rights to safety. This tension between active and activist citizenship is echoed in the literature on co-production. Like active citizenship, co-production can be motivated by reductive logics, making citizens responsible for co-producing services to meet their own communities' needs in the context of austerity and reduced provision of social resources. But co-production can also be more activist, when it opens up the value-based rationalities of policy making to political challenge and encompasses an 'additive logic' in which provision of social resources is sustained and combined with additional citizen action (Durose and Richardson, 2016).

Whilst there has been great success in the uptake of VAW as a social policy concern, the extent of user-led or 'additive logic' co-produced strategic planning and policy making for services that are supported by public money and statutory guidance is at best patchy. Abused women, in particular, are rarely recognised as a service user group (Mullender and Hague, 2005). The Istanbul Convention makes no specific reference to service users' involvement in VAW policy development. The funding and guidance from Welsh Government formerly available for service user regional groups is no longer available ${ }^{1}$ and this exacerbates the risk that lack of capacity will lead to limited representation of VAW service users in the policy arena. However, in Wales, an opening for political challenge to the dominant process of VAW policy making has arisen. The Welsh Government has an established agenda for service user involvement in identifying gaps and developing services to inform strategic development of VAW services (Welsh Government, 2008). The 2015 Act s16(1) requires ministers to 'consult such persons as they consider appropriate' regarding any draft statutory guidance in this field.

The duty to consult is a small opening for co-production at a policy level, and to transform this into an opportunity for 'a radically democratic alternative form of policy design' (Durose and Richardson 2016: 20) that may enable policy making to respond to a wide spectrum of needs among victims of VAW with more flexibility and responsiveness (ibid.), citizens would have to be included in ways that challenges the 'hierarchical ordering of expertise' (ibid.: 39) in which policy making by technocrats is privileged. Rather than starting with draft guidance, there is need for transversal politics and dialogue as 'knowledge based on just one positioning is "unfinished"' (Yuval-Davis, 1999: 956). Yuval-Davis' $(1994,2011)$ conception of transversal politics is a useful theoretical 
underpinning for Durose and Richardsons' (2016) conceptions of co-production as both approaches focus on developing shared values and visions, recognising power and valuing differences in knowledge positions. Yuval-Davis (1999: 96) argues that 'each participant in political dialogue' should be rooted in and reflexive about their own position and try to 'shift' themselves into 'the situation of those with whom they are in dialogue', acknowledging differentials of social, economic and political power.

This article explores the potential for a common perspective on key elements of 'effective' VAW service provision in Wales bringing together messages from two groups of 'persons who should be considered appropriate' to become involved in developing guidance under the 2015 Act - VAW service users, service providers and academic researchers (recognising that these identities are not mutually exclusive). These perspectives are not co-produced knowledge as our study falls far short of collaborative and dialogic approaches to research and service development. Rather, it 'uses empirical data from successful work', and shows there is potential for partners to gel and enthuse 'about their mutual passion' and calls for a focus on how such partnerships can be 'conceptualised and cultivated' (Hart and Wolff, 2006: 129) in the process of collaborative policy making. The article then considers how learning from this research could be combined with existing examples of practice to take steps towards 'transformative' and 'additive logic' co-production of VAW policy and funding allocation.

\section{Methods}

The research commissioned by the Welsh Government was to review VAW, sexual violence and domestic abuse services delivered across Wales (Berry et al., 2014). It embraced services covering all aspects of VAW, including female genital cutting (FGC), forced marriage and honour-based violence; domestic abuse (including LGBT relationships and elder abuse); sexual violence (including rape, sexual assault and harassment); and sexual exploitation (including prostitution and trafficking for sexual purposes). The remit was to include services for women and men as victims or perpetrators of all these different forms of gendered violence (Berry et al., 2014). Both service users and providers from a range of VAW services across Wales were invited to participate as respondents in the research; in the limited five-month timescale allocated for the study, we aimed to recruit twenty services users in two areas.

Different methods were employed in the wider study, but for this aspect of the project we aimed to include victims/survivors and perpetrators in focus groups to offer suggestions about improvements to service response. Interview schedules and vignettes were designed to elicit responses on three key questions: What services are available? What services should be available? What are the characteristics of a good quality service? As we were not soliciting views on personal experiences and wanted to take steps towards identifying shared ideas about potential solutions, focus groups were more appropriate than interviews. However, we were fully aware that new disclosures could still occur and thus implemented a protocol in order to respond appropriately to any such disclosures.

Despite a large proportion of services defining their function as protection, relatively few of the services worked with male and/or female perpetrators of violence when compared with those working with victims. Furthermore, as expected, services that 
worked with victims were largely working with female victims whilst perpetrator programmes served more male users than females. No or few services for male perpetrators and no or few services for female perpetrators were reported for many of the areas in Wales.

In order to recruit participants to the focus groups, VAW services in Wales assisted the researchers to convene and hold groups with fifty-three women from North and South Wales. Five groups were run in total and these included both women with extensive experience of using VAW services and those with limited experience of doing so; the groups included a substantial number of black, minority ethnic and refugee (BMER) women and women across a wide age range. No men or perpetrators took part in the focus groups, and had we recruited male victims or perpetrators they would have been interviewed separately (Kitzinger, 1995; Johnson, 2008).

The women were concerned about confidentiality and anonymity, and, in order not to compromise this, we took the decision not to collect demographic information and agreed that we would not offer any specific information that could lead to the services being identified. The focus groups utilised a semi-structured topic schedule and two vignettes depicting scenarios of domestic and sexual violence to generate discussion. We offered participants a selection of draw-write tools all of which were used by at least one group: drawing an ideal service; mind mapping and writing a pros and cons lists (Kreuger and Casey 2014). It was a messy and embodied process in many languages. However, as is often the way in focus groups (Kitzinger and Barbour, 1999) and to maximise participants' influence over the views they chose to share, the direction followed in the discussion was influenced by the participants so not all questions were asked in all groups and both vignettes were not consistently used in all groups.

In addition, semi-structured telephone interviews were conducted with thirty-one stakeholders in the VAW sector. These respondents were purposively selected to cover the range of relevant organisations in the public and independent sectors delivering VAW services across Wales. Eight were key strategic leads holding commissioning and/or policy roles and twenty-three were direct service providers in the VAW sector. In this article, the term 'service provider' (hereafter SP) refers to commissioners and direct providers and is used to distinguish them from the 'service user' (hereafter SU) (acknowledging that some SPs may have been SUs, and vice versa). The SPs participating in the interviews did not necessarily represent the specific services that these fifty-three SU participants accessed, but were rather selected for their ability to provide a national perspective on VAW services in Wales. In addition to concerns about identification of SU participants, there were also ethical dilemmas regarding identification of SPs due to the small size of the VAW sector within Wales and it was agreed that $\mathrm{SPs}^{\prime}$ names, job titles and organisations would not be identified. Ethical approval for the study was obtained from the University of Central Lancashire's Research Ethics Committee.

All interviews and focus groups were recorded and transcribed with informed consent from participants. Data were analysed using a thematic or grounded theory approach which both drew on the key questions that structured the interviews and allowed for the emergence of new themes and sub-themes (Charmaz, 2000). The research was not therefore co-produced, rather the focus on the potential of co-production emerged from our engagement with the data analysis, the policy context and the researchers' own interests in this area. 


\section{Results}

Two main themes were identified from the analysis of $\mathrm{SU} \mathrm{s}^{\prime}$ and $\mathrm{SPs}^{\prime}$ views of service delivery in Wales: the responsiveness of VAW services and the delivery of these services. These themes and associated sub-themes are discussed below. The findings illustrate the challenges for a sector that is being required to take on an expanded remit and respond to a wider spectrum of care needs while addressing diversity within the user population.

\section{Accessibility of services}

Whilst we aimed to explore views about the full range of VAW services, most of the SUs had accessed domestic abuse services and most of the general discussions addressed the delivery and responsiveness of these services. Many of the SUs felt that these services were 'hidden away' and that information about them was not sufficiently accessible. This view contrasted with the SPs' accounts of attempts to advertise and promote services through a wide range of media and outlets, including poster campaigns, leaflets, community events and through increasing use of social media. SUs asked: 'Why is it not advertised? It is not getting to the right places' and 'there is information but you have to know where to go for it'. One of the SUs commented: '[l] have lived here all my life and the only organisation I knew about was Women's Aid ... the other organisations, they are meant to be charities, they are not advertised.' This view was even more strongly held by the BMER SUs, many of whom had initially been unaware of VAW services and had only accessed them after seeking help with other issues, such as housing or residency. These women argued that making the services more prominent would also challenge the secrecy surrounding VAW which, they believed, would have a positive impact on public attitudes.

\section{Responsiveness to a range of service needs}

In terms of the responsiveness of services, a further concern raised by SUs was in relation to the cessation of support services once victims had come through the crisis period and had left a refuge. As one SU stated: 'Women have learned how to cope with the violence, whereas they haven't learned how to cope with the isolation that comes when you do leave. Support should be on-going when you leave, not just crisis.'

As is widely documented, VAW, domestic abuse and sexual violence have short-, medium- and long-term impacts (García-Moreno et al., 2005; Holt et al., 2008), and there are pressures on services to respond to these myriad needs across a continuum of care. In Wales, the transition towards a broader VAW agenda has met with some criticism from those worried that the sector risks losing its specialist knowledge, and these concerns were voiced by some of the SPs interviewed: 'providers will throw their hat into the ring in a commissioning process. And I think some of my fear is, as we move down that road, that it will dilute the specialism that is in the sector' (SP).

Many of the SUs argued that specialist expertise was required to deal with specific issues, such as FGC, as well as the varying demographics of women accessing services. For example, one of the young women argued for age-specific services, saying that: 'Coming into a room where there are lots of older people I would feel threatened.' Similarly, one of 
the organisations specifically for BMER women was commended by SUs for its knowledge and expertise on issues specific to BMER women, such as easy access to interpreters and interpreting services, and this contrasted favourably with other services:

the lack of interpretation in services, that is lacking. I've been in court, in Citizen's Advice Bureau ... these places, you know, even on the telephone line, the interpretation service, when they go there, that has put a lot of women off, they can't express themselves because English is not their first language. (SU)

These women described the problems of relying on interpretation services that did not understand, or were insensitive to, VAW. Discussions also focused on a general lack of understanding of women's environments and SUs suggested that there could be training to ensure staff 'know about different cultures' (SU). The extent to which services were perceived to be responsive to different groups, including whether they provided women-only and men-only services, as well as being culturally relevant, was identified as impacting on their accessibility and value for users. Most participants who expressed a preference stated that they needed women-only services and female staff. Some women were happy for men to be able to access the same services as women but only under specific conditions.

\section{Generic or specialist services}

This emphasis on diversity raises questions about the theoretical framework that informs service delivery: Should SPs start from conceptualising features common to all forms of VAW or adopt a view that the different manifestations of VAW require different input? One of the SPs argued strongly that there were commonalities across all forms of VAW and that the sector itself might be creating divisions where, in reality, there were more similarities than differences. This SP argued that the focus on the typology of violence forced the focus onto the victim rather than onto the perpetrator of the crime:

over the last few years, all national parties have moved towards the violence against women and girls approach. [but there is] the absolute resistance to the idea of violence against women and girls as a collective term for a set of crime types ... and not a description of victims ... the obvious and easiest way to do it, is to focus on the services that women need ... there's masses of overlap, in terms of the services that women need. (SP)

Despite the policy shift to a wider VAW remit, the Welsh service review found that the majority of the work in the sector was stratified by type of violence, and the majority of service provision continued to be focused on domestic abuse (Berry et al., 2014). However, SPs participating in the study felt that the broader VAW remit facilitated the wider identification of different forms of VAW, potentially increasing the number of referrals. It is often the case that victim/survivors only disclose the full range and extent of the violence and abuse they have experienced once they have received a positive response from a service. For example, as one SP explained, support for one form of abuse may lead to disclosures of others, 'that they wouldn't otherwise disclose if they hadn't been asked the question'. Thus, perhaps the picture is more complex, with a need either 
for better integration between services that provide for these different requirements or for all the services to develop a more holistic response at the same time as retaining the specialist response for specific forms of violence/abuse.

On a practical level, however, SPs feared that policy shift to a wider VAW remit had led to increased workloads, with generic services expected to work with cases that previously would have been referred to a specialist service. There were also concerns expressed by providers from specialist services that, whilst the remit had expanded, the level of expertise had not, so that some professionals were now working with women without having the requisite training or understanding of the issue. It was also argued that the time and training required for specialist providers to accumulate expert knowledge were at risk of being overlooked.

Ever-tightening budgets, increased caseloads and standardisation of services has resulted in a move towards confining the delivery of domestic abuse services to a period of twelve weeks. Both SUs and SPs recognised the limitations of the twelve-week model, which was described as leading to frustrations from SPs who had neither the budget nor autonomy in respect of time available to extend support. Some of the SUs discussed the peer support group they had established with support from their worker, to ensure they had a safe, friendly space to continue the friendships they had made during agency delivered group-work, and they recommended a national strategy to support this form of provision. Whilst this was a positive resource for the women, concerns were raised about how they managed the expectations of the group and how, for example, information could be shared and confidentiality maintained. This was of particular concern as the women attending the group were part of a small local community where there were complex inter-relationships between family members and where it was difficult to keep matters private.

\section{Delivery of services}

Unsurprisingly, the rural landscape of much of Wales was identified as a barrier to accessing services for some women due to lack of service provision, limited public transport and long travel distances. Similar problems have been identified by other studies in rural areas (McCarry and Williamson, 2009). Many of the SPs argued for peripatetic services in rural communities where 'it is about bringing the services to the victims instead of the victims to the services' (SP). Given the costs of outreach work, some services have developed online facilities, such as websites, to provide both information and interaction with practitioners, and, whilst this can increase the reach of services, many SUs were distrustful of online services and preferred telephone or direct face-to-face support.

An alternative approach implemented across Wales is the One-Stop-Shop model. This provides users with an array of services under one roof, including for example: advocacy, legal advice, support with relocation and housing, therapeutic or recovery groups and support for children. One SP argued that it had been an extremely positive development:

it is a multiagency centre ... we've got Social Services and Health and the likes, all based in one building ... the working together and the partnership working, has literally increased tenfold since we've been here. 
Variations in the delivery of the model across Wales were described by SPs. SUs who had accessed a One-Stop-Shop appreciated these organisations, particularly those that offered specialist support to BMER women as they offered continuity of service. Indeed, some of the SUs offered ideas about their 'perfect' service response, constructing their answers around a drawing of a model One-Stop-Shop. Whilst the specificities varied, the One-Stop-Shop described by the SUs encompassed a range of services, such as housing, health services and the police, in addition to nonstatutory services, such as Women's Aid and other more social elements such as a gym. In the context of anxieties about confidentiality, many conceptualised their ideal One-Stop-Shop as contained within a generalist or more universal context, such as being housed within a Civic Centre in order to be 'non-stigmatising' and to 'protect confidentiality'.

\section{Funding arrangements}

Welsh Government funding for VAW services is channelled directly to Local Authorities, which then establish commissioning arrangements. However, most VAW sector services, with the exception of those few organisations funded solely by the Welsh Government, were reliant on funding from multiple and diverse sources. Overall, the funding situation was described as precarious. The main concerns reported by SPs were the lack of secure funding streams, the ubiquity of short-term funding and part-time contracts which resulted in high job insecurity, high staff turnover, higher training costs and instability of services across the sector. Short-term funding also meant that staff hours were spent on securing funding rather than delivering service.

In response to these difficulties, one provider suggested that the sector could encourage more collaborative partnership working. However, commissioning arrangements tended to foster a more competitive landscape. For example, whilst a number of SPs welcomed joint commissioning and joint 'ownership and leadership', it was also noted by a SP that 'we're in a climate where we're all competing, you know, all my closest colleagues in the sector are also my competitors, which doesn't make it easy'.

\section{Discussion}

SPs identified gaps in service provision for BMER women, women in rural areas, male victims, children and young people, older women, disabled women, adult survivors of childhood sexual abuse, gypsy/traveller communities and women with additional needs. SUs recommended that information about services should be more widely available, despite providers' accounts of work undertaken on publicising services. SUs also recommended that providers developed services that were sensitive to intersecting experiences of gender, ethnicity, language, culture and rurality. Both SUs and SPs wanted more responsive services that would fill some of the identified gaps as well as interventions that were not limited to twelve weeks. One-Stop-Shops were seen to provide accessibility and continuity by SUs, and the review (Berry et al., 2014) recommended that these be robustly evaluated in Wales. There is a potential tension, however, between SUs' accounts of their service requirements and the perspectives of those providers who were perhaps more focused on cost. 
Given these largely shared perspectives on services expectations, co-production at a policy level might start by developing these as a set of strategic objectives, concerned with: accessibility, availability of service responsive to the range of identified needs and crimes, information about services, availability of same-gender services and staff, out-of-hours provision, on-going support outside of refuge and post twelve week interventions, levels of secure resources and collaboration rather than competition between services. These shared perspectives might also provide a set of indicators for consistently evaluating individual services across Wales, concerned with awareness and capacity within statutory/generic services such as housing, health, and the police; confidentiality; and training of staff to enable all of this. This idea is not revolutionary; indeed the Department for International Development (DfID) describe one of the key principles for developing national Violence Against Women and Girls (VAWG) indicators: 'Ask women to provide input and validate indicators on VAWG programming as they may be able to identify additional or unconventional measures of change and challenge project indicators as unsuitable or unhelpful' (DfID, 2012: 19).

The preparation and planning of the national and local strategies (2015 Act, s3 and s4) and the development of national indicators (2015 Act, s11 and s12) are foreseen, but preparation of truly shared strategies and indicators would require resolution of the points of tension raised in the study around visibility, specialist provision housed in generic or specialist services and the balance of on-line versus face-to-face services. A participatory approach to the present study could have been beneficial as it might have enabled differing perspectives to be explored through shared data analysis (Bergold and Thomas, 2012). In policy making, focus on transversal dialogue (Yuval-Davis, 1997) may be productive. Although Yuval-Davis argues that it is not necessary to have a shared identity to develop a common political goal, it is relevant that perhaps more than in any other sector, VAW services are provided by women who have themselves had experience of the particular needs that women bring to the services. And, given prevalence levels, it is likely that some members of the Welsh Government and policy making staff may themselves have experience of VAW. Some shared experience does not equate with shared political positions, and attention to what different policy actors might be expected to advocate for and the relations of power in transversal dialogue is necessary (YuvalDavis, 2011). It is possible that a SU advocate for SU perspectives would put a stronger case for users' views than a policy maker charged with juggling the competing demands of financial and other political priorities, even if that policy maker had used VAW services. Facilitating processes in which all policy actors engage in 'rooting' and 'shifting' between different positions (Yuval-Davis 1994) is therefore necessary. This may help development of mutual trust and unpick any internalising of assumptions about 'what works', which advocates for SUs who become part of the policy making machinery may have internalised along their journey towards gaining enough to change society (Yuval-Davis, 2011: 14).

A 'transformative' (Needham and Carr, 2009) approach to developing strategies and indications would require more than just transversal dialogue; SUs and professionals would have to jointly decide on indicators, rather than users making suggestions that policy makers then accept or reject.

An opportunity for more 'transformative' co-production has been missed in the draft guidance on strategic collaboration which was under consultation at the end of 2015, following the publication of the 2015 Act. The section entitled 'a victim focus' evidence from research ends with a graphic concerned with effective partnership working that 
states 'The experience of SUs should regularly and systematically be used to inform the partnership on the effects of its work and to suggest improvements' (Welsh Government, 2015: 15). Again, there is no trace here of a transformative approach to co-production, rather the SUs are positioned as informants rather than creators of innovative solutions and co-making decisions about the use and distribution of resources.

Moving beyond consultation to enable 'a relocation of power and control' towards 'user-led mechanisms of planning, delivery, management and governance' (Needham and Carr, 2009: 6) may seem like a distant goal, but clear factors enabling this approach to policy making are indicated by research and practice. Public organisations must be open to co-production and provide clear incentives for co-creation (Voorberg et al., 2015). Shared spaces of dialogue, open to all women and men with experience of abuse and violence, and SPs and commissioners who could define their own terms of collaboration are needed. Achieving this requires government officials to expose themselves to the risk that it may be a challenging process, and there is a risk that co-production could be disabled where attention focuses on questioning the legitimacy of representatives (Burall and Hughes, 2016). Here, again, Yuval-Davis (1994) is helpful, as she underlines the point that in transversal dialogue participants are not representatives but advocates. The timing of and timescales for policy decision making must be shared and understood (Burall and Hughes, 2016). Co-option must be resisted and contestation embraced (Steele, 2016) but flexibility to circumstances must be maintained through adopting 'grammar' or forms of action 'that enables resistance and collaboration, according to what secures better policy outcomes' (Durose and Richardson, 2016: 210).

To achieve the shared goals articulated through transversal dialogue, some grammar of less collective forms of SU participation may be needed, especially if it enables involvement in moments of financial decision making and agenda setting. In some voluntary sector VAW organisations SUs become part of management committees and participate in decision making about resource allocation; it is however rare in statutory services or national policy and funding committees. But steps towards agenda setting have already been taken within the Welsh Government, with at least one SU sitting alongside SPs and advisors in the task and finish group that wrote to The Welsh Government's proposed 'Ending Violence Against Women and Domestic Abuse (Wales) Bill': Recommendations from the Task and Finish Group (Robinson et al., 2012). The super empowerment of one user to the exclusion of multiple voices may evoke criticism (Beresford, 2008), but as the role of the specialist advisor on VAW was created by the 2015 Act, a better balance may be achieved if a SU advocate were employed alongside her. This might then reflect more closely the approach adopted in another section of the Welsh Government, where the Supporting People Regional Collaboration Committees (which sets commissioning plans and spending priorities) requires 'a current SU, ex-SU or a person chosen by SUs to represent them' and this representative must have adequate administrative support in the same way as other board members (Welsh Government, 2013: 18).

\section{Conclusion}

In contrast with other groups of SUs who have felt cautious about entering into co-production with policy-makers and state decision makers, who in the past have contributed to their experience of discrimination (Farr, 2012), the history of user 
involvement in co-producing VAW services suggests that there would be open engagement at a policy making level. Indeed, there would be no lack of participants judging by the enthusiasm of those women taking part in the focus groups held for the research reported here. The findings show real opportunities for shared standards for service delivery to be developed, and this suggests that providers and users may be sufficiently empathetic towards each other's perspective, whilst grounded in their own (Yuval-Davis, 1997), to reach shared solutions to the tensions in planning service delivery that remain. To avoid a neo-liberal approach of holding SUs responsible for co-production (Scourfield, 2015), the crucial next step towards transformational coproduction of VAW planning must then be to hold governments, policy makers and commissioners to account, to show that they are open to and embrace opportunities for co-production of policy and genuine power sharing. Learning from other examples in Wales and from UK recommendations, this might reasonably start by developing different grammars of engagement for VAW SUs to contribute to open discussions through transversal dialogue and to act more individually as advocates in decision making around service standards and funding priorities. Co-production of further research in this field would also be beneficial as knowledge can enable challenge of habitual ways of defining evidence bases for policy making.

If the Welsh government takes on board these arguments in the development of future guidance, it may, through a quadruple devolution of power (to a small nation, local authorities, professionals and SUs), make a further break with the UK policy climate and move closer to transformative co-production. The acid test of these steps towards transformative co-production will be, however, whether sufficient resources can be put in the hands of SUs and frontline staff for services to be developed, or refined, that would meet the standards they might set. Further steps towards transformative co-production may then relate here to the need for SUs, and those professionals working with them, to challenge the orthodoxy of austerity. In the current international context of insufficient funding for VAW services, these findings may prove relevant beyond the UK.

\section{Acknowledgements}

The research on which this article is based was funded by an award made by the Government of Wales. The views expressed here are however those of the authors and do not necessarily reflect the views of the Government of Wales.

\section{Note}

1 Although the 2015 consultation paper on multi agency working suggests guidance can be found on the Safer Lives website, it cannot be found.

\section{References}

Beresford, P. (2008) 'Service users: individualised involvement or collective action?', A Life in the Day, 12, $4,13-15$.

Bergold, J. and Thomas, S. (2012) 'Participatory research methods: a methodological approach in motion', Forum: Qualitative Research, 13, 1, art. 30.

Berry, V., Stanley, N., Radford, L., McCarry, M. and Larkins, C. (2014) Building Effective Responses: An Independent Review of Violence against Women, Domestic Abuse and Sexual Violence Services 
in Wales, Wales: Welsh Government Social Research, http://clok.uclan.ac.uk/10728/1/140430violence-against-women-domestic-abuse-sexual-violence-services-FULL\%20report\%20EN.pdf [accessed 13.02.2017].

Bovaird, T., Stoker, G., Jones, T., Loeffler, E. and Roncancio, M.P. (2016) 'Activating collective co-production of public services: influencing citizens to participate in complex governance mechanisms in the UK', International Review of Administrative Sciences, 82, 1, 47-68.

Burall, S. and Hughes, T. (2016) 'The hidden politics of policy design', in C. Durose and L. Richardson (eds.), Designing Public Policy for Co-Production Theory, Practice and Change, Bristol: Policy Press, 71-80.

Butler, E. (2015) Welsh Women's Aid Response to the Spending Review Announcement on Funding Women's Services, Wales: Welsh Women's Aid, http://www.welshwomensaid.org.uk/images/ stories/documents/Emma/WWA_respon se_to_SR_announcement_on_womens_services.pdf [accessed 25.01.2016].

Charmaz, K. (2000) 'Constructivist and objectivist grounded theory', in N. K. Denzin and Y. S. Lincoln (eds.), Strategies of Qualitative Inquiry, Thousand Oaks, CA: Sage, 509-35.

Department for International Development (2012) Violence against Women and Girls CHASE Guidance Note Series Guidance Note 3: Guidance on Monitoring and Evaluation for Programming on Violence against Women and Girls, https://www.gov.uk/government/uploads/system/uploads/ attachment_data/file/67334/How-to-note-VAWG-3-monitoring-eval.pdf [accessed 07.03.16].

Durose, C. and Richardson, L. (2016) Designing Public Policy for Co-Production Theory, Practice and Change, Bristol: Policy Press.

Farr, M. (2012) 'Collaboration in public services: can service users and staff participate together', in M. Barnes and P. Cotterell (eds.), Critical Perspectives on User Involvement, Bristol: Policy Press, 79-88.

García-Moreno, C., Jansen, H. A. F. M., Ellsberg, M., Heise, L. and Watts, C. (2005) WHO Multi-Country Study on Women's Health and Domestic Violence against Women: Initial Results on Prevalence, Health Outcomes and Women's Responses, Switzerland: World Health Organization.

Hague, G., Mullender, A., Aris, R. and Dear, W. (2001) Abused Women's Perspectives: The Responsiveness of Domestic Violence Provision and Inter-Agency Initiatives, ESRC Full Research Report, L133251017, Swindon: Economic and Social Research Council.

Hague, G. and Mullender, A. (2006) 'Who listens? The voices of domestic violence survivors in service provision in the United Kingdom', Violence Against Women, 12, 6, 568-87.

Hart, A. and Wolff, D. (2006) 'Developing local "communities of practice" through local communityuniversity partnerships', Planning Practice and Research, 21, 1, 121-38.

Hooks, B. (1982) Ain't I A Woman: Black Women and Feminism, London: Pluto Press.

Holt, S., Buckley, H. and Whelan, S. (2008) 'The impact of exposure to domestic violence on children and young people: a review of the literature', Child Abuse and Neglect, 32, 8, 797-810.

Home Office (2014a) A Call to End Violence against Women and Girls Action Plan 2014, https://www.gov.uk/government/uploads/system/uploads/attachment_data/file/287758/VAWG_ Action_Plan.pdf[accessed 27.04.2015].

Home Office (2014b) Violence Against Women and Girls Policy, https://www.gov.uk/government/policies/ ending-violence-against-women-and-girls-in-the-uk\#bills-and-legislation [accessed 27.04.2015].

Isin, E. (2009) 'Citizenship in flux: the figure of the activist citizen', Subjectivity, 29, 367-88.

Johnson, M. (2008) A Typology of Domestic Violence: Intimate Terrorism, Violent Resistance, and Situational Couple Violence, Lebanon, NH: Northeastern University Press.

Kitzinger, J. (1995) 'Qualitative research: introducing focus groups', British Medical Journal, 29, 311, 299-302.

Kitzinger, J. and Barbour, R. (1999) Developing Focus Group Research: Politics, Theory and Practice, Thousand Oaks, CA: Sage.

Krueger, R. A. and Casey, M. A. (2014) Focus Groups: A Practical Guide for Applied Research, London: Sage. 
Matczak, A., Hatzidimitriadou, E. and Lindsay, J. (2011) Review of Domestic Violence Policies in England and Wales, London: Kingston University and St George's, University of London.

McCarry, M. and Lombard, N. (2016) 'Same old story? Children and young people's continued normalisation of violence against women', Feminist Review (Special Issue: Violence), 112, 12843.

McCarry, M. and Williamson, E. (2009) Violence Against Women in Rural and Urban Areas, Bristol: University of Bristol.

Mullender, A. and Hague, G. (2005) 'Giving a voice to women survivors of domestic violence through recognition as a service user group', British Journal of Social Work, 35, 1321-41.

National Assembly for Wales (2015) Violence against Women, Domestic Abuse and Sexual Violence (Wales) Act 2015, http://www.senedd.assembly.wales/mglssueHistoryHome.aspx?IId=10028\&AIID= 17668 [accessed 13.02.17].

National Institute for Health and Care Excellence (NICE) (2013) Review of Interventions to Identify, Prevent, Reduce and Respond to Domestic Violence, http://www.nice.org.uk/ nicemedia/live/12116/64791/64791.pdf [accessed 03.03.2014].

Needham, C. and Carr, S. (2009) SCIE Research Briefing 31: Co-production: An Emerging Evidence Base for Adult Social Care Transformation, London: Social Care Institute for Excellence, http://www.scie. org.uk/publications/briefings/briefing31/ [accessed 13.02.2017].

Robinson, A., Brisbane, J., Farrar, J., Hardy, P., Jones, B., Pickles, J. and Shepherd, J. (2012) The Welsh Government's proposed 'Ending Violence Against Women and Domestic Abuse (Wales) Bill': Recommendations from the Task and Finish Group, Final Report, http://www.cardiff.ac.uk/ socsi/resources/Robinson\%20et\%20al\%20(2012)\%20Task\%2 0and\%20Finish\%20Group\%20Report .pdf [accessed 07.3.2016].

Scourfield, P. (2015) 'Implementing co-production in adult social care: an example of meta- governance failure?', Social Policy and Society, 14, 4, 541-54.

Smith, K. (ed.) (2012) Osborne, S., Lau, I. and Britton, A., Homicides, Firearm Offences and Intimate Violence 2010/11 (Supplementary Volume 2 to Crime in England and Wales 2010/11), Home Office Statistical Bulletin 02/12, https://www.gov.uk/government/uploads/ system/uploads/attachment_data/file/1164 83/hosb0212.pdf [accessed 07.03.2016].

Social Care Institute for Excellence (SCIE) (2015) Co-production in Social Care: What it is and How to Do it, Social Care Institute for Excellence (SCIE) Guide 51, http://www.scie.org.uk/ publications/guides/guide51/ [accessed 25.01.2016].

Steele, J. (2016) 'Doing politics to build power and change policy', in C. Durose and L. Richardson (eds.), Designing Public Policy for Co-Production Theory, Practice and Change, Bristol: Policy Press, 115-24.

Towers, J. and Walby, S. (2012) Measuring the Impact of Cuts in Public Expenditure on the Provision of Services to Prevent Violence against Women and Girls, Lancaster University Report for Northern Rock Foundation and Trust for London.

Voorberg, W. H., Bekkers, V. J. J. M. and Tummers, L. G. (2015) 'A systematic review of co- creation and co-production: embarking on the social innovation journey', Public Management Review, 17, 9, $1333-57$.

Walby, S. (2004) The Cost of Domestic Violence, London: The Woman and Equality Unit, http://www.devon.gov.uk/de/text/cost_of_dv_report_sept04.pdf [accessed 07.03.2016].

Walby, S. (2009) The Cost of Domestic Violence: Up-date 2009, Executive Summary, http://www. lancs.ac.uk/fass/sociology/profiles/34/ [accessed 20.11.2015].

Walby, S. (2014) 'Measuring the cost of gender-based violence', Seminar to the Connect Centre, University of Central Lancashire, 9 December.

Welsh Government (1998) Government of Wales Act 1998, http://www.legislation.gov.uk/ukpga/1998/38/ pdfs/ukpga_19980038_en.pdf [accessed 13/02/17].

Welsh Government (2005) Tackling Domestic Abuse: The All Wales National Strategy, Welsh Government, http://www2.nphs.wales.nhs.uk:8080/ChildProDocs.nsf/0/561999da11052377802579640059be8b/ \$FILE/Domestic\%20Abuse\%20Strategy.WAG\%202004.pdf [accessed 13.02.2017]. 
Welsh Government (2008) Domestic Abuse Inquiry Report, Welsh Assembly Government, http://www.assembly.wales/NAfW\%20Documents/cc3_domestic_abuse_inquiry_report_-_e_-_final. pdf\%20-\%2002122008/cc3_domestic_abuse_inquiry_report_-_e_-_finalEnglish.pdf [accessed 25.01. 2016].

Welsh Government (2010) Right to be Safe Strategy, Welsh Government, http://www. injuryobservatory.net/wp-content/uploads/2012/09/Violence-Strategy- 2010-New-Strategy.pdf [accessed 20.11.2015].

Welsh Government (2012) Consultation on Legislation to End Violence against Women, Domestic Abuse and Sexual Violence (Wales), http:/gov.wales/docs/dsjlg/consultation/ 121126evawdaconsultationen.pdf [accessed 07.03.15].

Welsh Government (2013) Supporting People Programme Grant (SPPG), Welsh Government, http://gov.wales/docs/desh/publications/130607sppgrantguideen.pdf [accessed 18.09.2015].

Welsh Government (2014) 'The Right to be Safe Strategy Annual Report 2013-14', http://wales.gov.uk/docs/dsjlg/publications/commsafety/right-to-be-safe-annual-report-2013-14-v2en.pdf [accessed 07.03.2016].

Welsh Government (2015) Violence against Women and Domestic Abuse, http:/gov.wales/topics/ people-and-communities/communities/safety/domesticabuse/?lang=en [accessed 28.04.2015].

Women's Aid (2013) Women's Aid Warns of Crisis in Domestic Violence Services, http://www.womensaid.org.uk/domestic-violence-press information.asp?itemid=3194\&itemTitle= Women\%92s+Aid+warns+of+crisis+in+dom estic+violence+services\&section= $0001000100150001 \&$ sectionTitle=Press+releases [accessed 25.01.2016].

Welsh Women's Aid (2016) Welsh Women's Aid's Manifesto Priorities for Political Parties in Wales 2015-16: Preventing Violence Against Women in Wales, http://www.welshwomensaid.org.uk/ images/Welsh_Womens_Aid_-Manifesto_FINAL.pdf [accessed 25.01.2016].

Yuval-Davis, N. (1994) 'Women, ethnicity and empowerment', in K. K. Bhavnani and A. Phoenix (eds.), Shifting Identities Shifting Racisms: A Feminism and Psychology Reader, London: Sage.

Yuval-Davis, N. (1997) 'Citizenship: pushing the boundaries', Feminist Review, 57, 4-27.

Yuval-Davis, N. (1999) 'What is "transversal politics"?', Soundings, 12, Summer, 92-6.

Yuval-Davis, N. (2011) Power, Intersectionality and the Politics of Belonging, FREIA Working Paper, Series No. 75 FREIA - Feminist Research Center in Aalborg, Aalborg University, Denmark, http://vbn.aau.dk/ws/files/58024503/FREIA_wp_75.pdf [accessed 13.02.2017]. 